
www.globaljournalseries.com, Email: info@globaljournalseries.com

\title{
UTILIZATION OF INSECTICIDE TREATED NETS AMONG PREGNANT WOMEN AND MOTHERS WITH UNDER FIVE CHILDREN IN IKOT OMIN COMMUNITY, CALABAR, NIGERIA
}

\author{
E. F. ASUQUO, O. B. EDET, P. E. SAMPSON- AKPAN, E. DUKE, A. D. NSEMO AND C. I. AJAH
}

(Received 15 November 2016; Revision Accepted 15 December 2016)

\begin{abstract}
Malaria is mostly endemic in tropical environments and has caused several still births and deaths particularly among children. Effective control of malaria infection reduces maternal and infant morbidity and mortality rate in pregnant women and children (0-5yrs). A promising strategy has been the utilization of insecticide treated nets among these groups of persons. A mixed method study was carried out in Ikot Omin community in Cross River State, Nigeria to authenticate the effectiveness of the net utilization. Four specific objectives were developed to guide the study. Data were elicited from 225 respondents through the use of structured questionnaires and focus group discussions. The quantitative and qualitative data were analyzed using SPSS 16.0 and thematic analysis methods respectively. The results showed that the prevalent harsh and dry weather condition was the major barrier to utilization of ITN in the community. A focused communication strategy to address this challenge has been suggested. The possibility of provision of steady light supply through the use of solar power in the homes by those who can afford it can be explored as a remedy for promoting consistent use of ITN by pregnant women and under five children in this community.
\end{abstract}

KEYWORDS: Insecticide treated nets, pregnant women, mothers, Ikot Omin, Nigeria

\section{INTRODUCTION}

Malaria is highly endemic in sub-Saharan Africa including Nigeria (Killeen et al., 2006; WHO, 2017). It has been widely observed that malaria threatens the lives of more than 500 million Africans and exerts such enormous public health burden that has resulted in the continued under-development of the continent as a whole (Killeen et al., 2006; Desai et al., 2007; WHO, 2017). The persistent endemic nature of malaria is attributed to climatic conditions which are ideal for breeding of the mosquitoes, though some degree of immunity is developed during the first decade of life. Despite this immunity, manifested by a higher prevalence and intensity of parasitaemia (Mbonye et al., 2006), the use of insecticide (permethrin)-treated bed nets (ITNs) has proven to be an effective method of reducing malarial attack and mortality associated with this infection (Koudou et al., 2010; Mboera et al., 2007; Murphy and Breman, 2001; WHO, 2002). Previous studies of ITNs efficacy trials in sub-Saharan Africa revealed that correct use of ITNs in children 0-5 years can save six lives in every 1000 (Harvey et al., 2008; Guyatt and Snow, 2002; Lengele,2004). In western Kenya, it was discovered that an estimated 34.5 lives could be saved per 1,000 infants protected with insecticides treated bed nets (Alaii et al., 2003). These tremendous results could also be attained in Nigeria if mothers effectively utilize the bed nets freely distributed to them by government.

Many factors affect the utilization of bed nets. Past studies have shown that the cost of ITNs, followed by their non-availability were major constraints to their use (Afolabi et al., 2009; Alaii et al., 2003; Chuma et al., 2010). Report by Alaii et al. (2003) from western Kenya indicated that, both age and temperature determined the probability that an individual will use the ITN and that people are less likely to use ITNs when it is hot while older people are more likely to use ITNs than young children. The leading single reason for non-adherence among the under-five children in this Kenyan study was that the net was "too hot". A group of researchers in Nigeria carried out a cross-sectional household survey on the use of ITNs from August 1 - 14, 2007, coinciding with the second raining period of the year and a time of high malaria transmission during the wet season (Afolabi et al., 2009). The authors compared household possession and use of mosquito nets between two ecologically distinct rural regions in Southern and Northern Nigeria and reported that significantly lower

E. F. Asuquo, Department of Nursing Science, Faculty of Allied Medical Sciences, University of Calabar, Calabar, Nigeria.

O. B. Edet, Department of Nursing Science, Faculty of Allied Medical Sciences, University of Calabar, Calabar, Nigeria.

P. E. Sampson- Akpan, Department of Nursing Science, Faculty of Allied Medical Sciences, University of Calabar, Calabar, Nigeria.

E. Duke, Department of Nursing Science, Faculty of Allied Medical Sciences, University of Calabar, Calabar, Nigeria

A. D. Nsemo, Department of Nursing Science, Faculty of Allied Medical Sciences, University of Calabar, Calabar, Nigeria.

C. I. Ajah, Department of Community Health, College of Health Technology, Calabar, Nigeria. 
proportion of households in the Sahel Savannah Region located in the North possess and utilized treated or untreated mosquito nets than those in the Niger Delta Region located in the South. Although the study did not explore the contribution of climatic condition to utilization of the nets, the Sahel Savannah region with a lower utilization rate has a hotter and harsher weather condition compared to the Niger Delta region.

In cold regions, the finding is reversed as reported in the study carried out in Mestizo communities in Peru (Harvey et al., 2008;Alaii et al., 2003; Lengeler, 2004). The transparent nature of the net was another constraint mentioned by the Peruvian women. Thus, in circumstances where families with children are living in a one room apartment, the use of a transparent net was seen as intrusion into their privacy (Harvey et al., 2008). Data sets from 15 sub-Saharan Africa (SSA) countries show that access to ITNs is still a major limitation within most of the countries analyzed (Alaii et al., 2003). Only three countries were found to have achieved greater than $25 \%$ coverage of ITN possession among households with a child younger than 5 years of age. The report further suggested that, within ITN-owning households, many children and pregnant women are still not sleeping under the nets. Nine out of the fifteen countries analyzed, less than one half the children in such households were using the nets, while in four out of fourteen countries studied less than one half the pregnant women were using the nets (Eisele et al., 2009). The proportion of children that slept under an ITN the previous night within ITN-owning households ranged from $27.6 \%$ in Zimbabwe (2003) to $71.2 \%$ in Kenya (2006). ITN use among pregnant women was even more pronounced within ITN-owning households, with eight out of the fourteen countries analyzed showing ITN use among pregnant women greater than $60 \%$. The proportion of pregnant women using an ITN, within ITNowning households, ranged from $29.1 \%$ to $82.3 \%$, within Zimbabwe and Kenya, respectively while the proportion of ITN-owning households with no one sleeping under one ranged from $8.7 \%$ to $52.2 \%$ (Eisele et al., 2009). Possession and use of ITNs has not been widely studied in Cross River state, Nigeria. The purpose of this study is to investigate the level of utilization of insecticide treated bed nets (ITNs) and associated factors among pregnant women and under five children in Ikot Omin community, Nigeria

\section{MATERIALS AND METHODS}

\section{Study design}

The study design utilised a mixed method study involving a quantitative descriptive cross-sectional survey and a qualitative descriptive aspect. The study was carried out between June 2008 and February 2009. The period covers both rainy and dry seasons in Nigeria. The researchers particularly employed the triangulation method to obtain different but complementary data on the phenomenon under investigation

\section{Study setting and study population.}

Ikot Omin is a community with a population of about 26,026 persons located at the northern part of Calabar. It is dominated by the Quas (61\%) and the Ibibios (34\%). Other ethnic groups include the Ibos, Hausas and Yorubas (5\%). Most of the inhabitants are subsistence farmers, with some fishermen and traders of perishable foods including cereals and tubers. Given the climatologically cycle and the size of the Nigeria in general, there is a significant change in total annual rainfall across Nigeria, both from the South to the North. The highest total precipitation is in the South, along the coastal states of Lagos, Bonny and Calabar where the Ikot Omin community is located. Nigeria has a mean annual rainfall of more than 4,000 millimeters. Rainfall occurs year-round with two main peaks: the long rainy season between April and August and the short rainy season between September and October. The temperature range in Nigeria is between 22 and $33^{\circ} \mathrm{C}$ with an average of $26.4{ }^{\circ} \mathrm{C}\left(80{ }^{\circ} \mathrm{F}\right)$ and a relative humidity ranging between 80 to $88 \%$ (Fig.1). With this hot moist climate, multiplication of mosquitoes is encouraged, which makes malaria infection endemic in the country. This district was selected for the study because malaria is endemic in the community. There is a government comprehensive health centre in the community to meet the health needs of the inhabitants including that of pregnant women and mothers with under-five children.

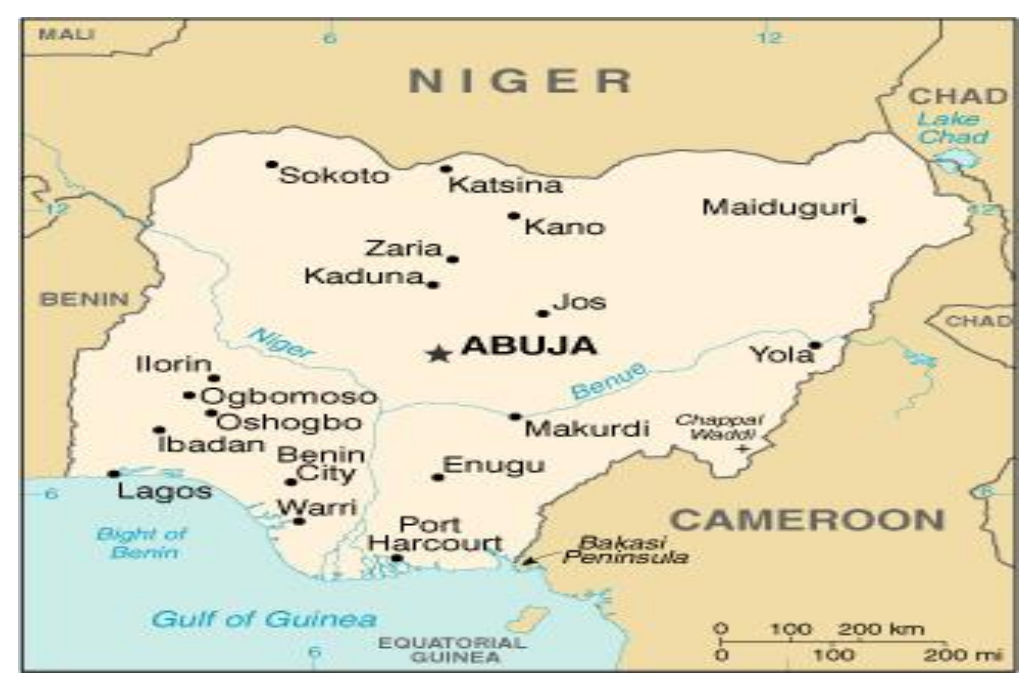

Fig. 1: Map of Nigeria showing the study area, Calabar in the South-South zone. 


\section{Sample and sampling technique}

Simple random sampling technique was used to select 225 mothers with 795 children aged $0-5$ years, who patronized the Comprehensive Health Centre who were also resident in Ikot Omin community.

\section{Method of data collection}

Data were collected using a structured questionnaire and Focus Group Discussion (FGD) guide. Three FGD sessions were held comprising of about 6 to 10 participants each. The FGD facilitated participant's expression of their perceptions on the phenomenon of interest in an open, free, relaxed format. It also helped to examine unconscious mechanisms operating within participants that have impacted their life's behavior on the use of ITN despite its advantages. The questionnaire and FGD guide explored the following areas; knowledge, attitude, utilization and barriers related to the use of ITN as a malaria preventive intervention.

\section{Method of Data analysis}

Data were analyzed using SPSS (16.0). Attitude was scored as follows: score of between 17 - 35 was rated as favorable attitude, while score of 0 - 16 was rated as unfavorable attitude. Thematic analysis was used for coding and categorizing data into themes. The qualitative data was first transcribed, followed by line-byline coding of the entire transcripts. Data relevant to each code were collated. The next stage involved searching for themes by collating codes into potential themes and gathering all data relevant to each potential theme. The final stage entailed sorting the themes and codes to make sure that they were related to the main idea.

\section{RESULTS}

\section{Demographic variables}

Table 1 shows that many, $126(56.0 \%)$ of the respondents were aged between 26 and 35 years. while $63(28 \%)$ were aged between $15-25$ years and 36 (16.0\%) were between $36-45$ years. There were 795 children between ages 0 to 5 years, 366 (46.04\%) were between 0 - 1years, $311(39.12 \%)$ children were between 2 to 3 years, while 118(14.84\%) were between 4 to 5 years. Among the 225 women recruited into the study, 79 (35.11\%) were pregnant while 146(64.89\%) were not pregnant.

One hundred and twenty-six $126 \quad(56.0 \%)$ respondents were married, 54(24\%) were single, while $45(20.0 \%)$ respondents were either divorced or widowed. All the respondents had children and 198 (88.0\%) were Christians while 27 (12.0\%) were Moslems. Most 126 (56.0\%) of the respondents had primary and secondary education while only $54(24.0 \%)$ had tertiary education, $45(20.0 \%)$ had no formal education. Many, $81(36.0 \%)$ of the respondents were civil servants while $63(28.0 \%)$ were full time house wives; others were either business women or traders. Most 108 (48.0\%) of the respondents earned below N10, 000.00 monthly; 81 (36.0\%) earned between N11, 000.00 and N20, 000.00 while only 27 (12.0\%) earned over N31, 000.00. 
Table 1: Distribution of respondents by socio-demographic characteristics

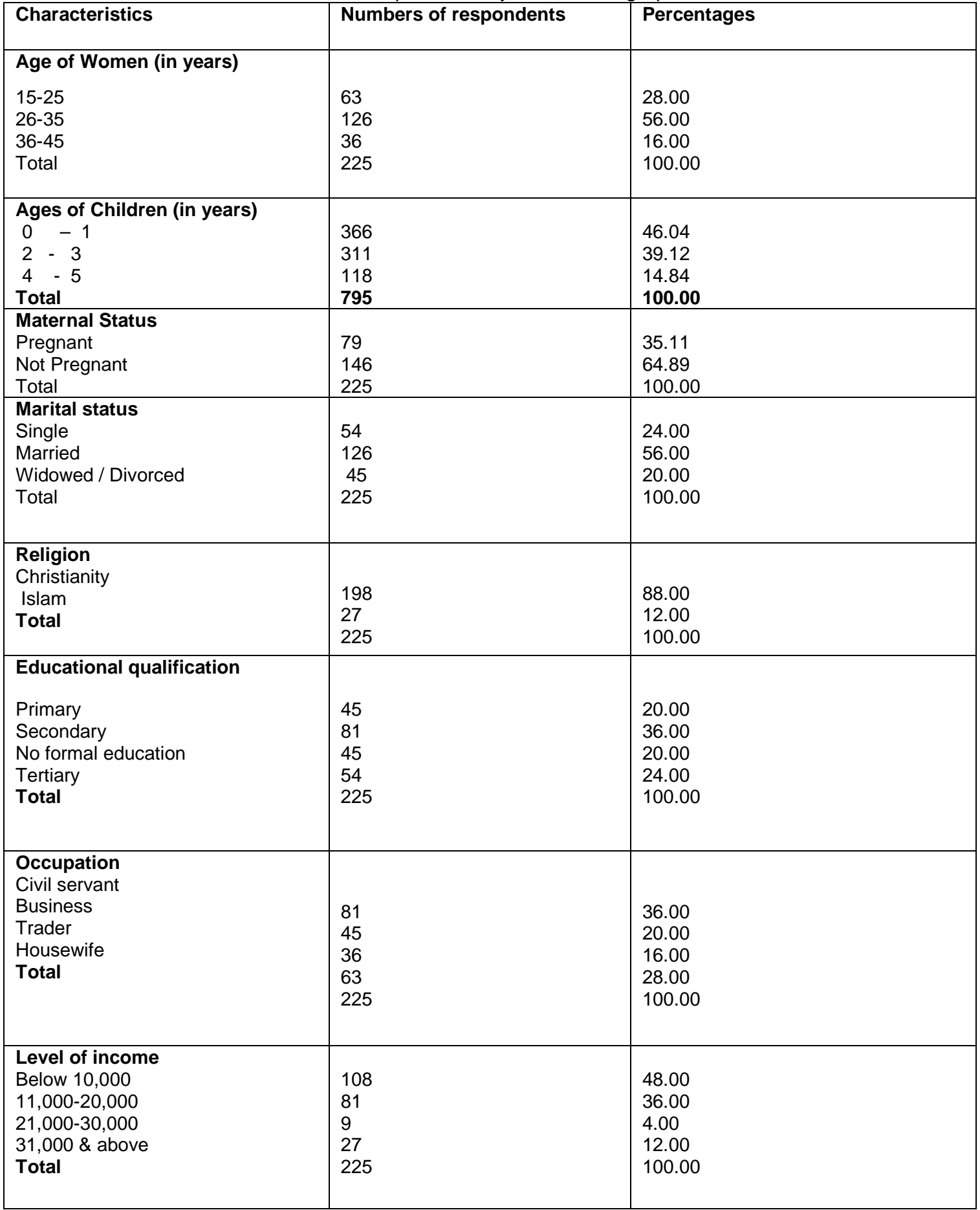

\section{Awareness of insecticide treated bed nets (ITNs)}

The level of awareness of ITN was generally high, particularly among those who have been patronizing the health centre for reproductive health services as illustrated in Fig.2. Majority, 180 (80.0\%) of the respondents have heard of ITN either through the health facility, radio/television or through a friend. A discussant stated "there is no clinic day that the nurses do not show us and they always tell pregnant women and children to always sleep under it'. Participants' knowledge of ITN was also high because they knew where to obtain ITN and stated its correct use. They mentioned that ITN is used either for prevention of malaria attack or for prevention of mosquito bites. However, $45(20 \%)$ of the respondents were not aware of its existence and mechanism of action. Poor knowledge was mostly peculiar to respondents who have not been patronizing the health facilities and were seeing the treated beds nets for the first time as stated: "well I am seeing this for the first time; I do not know what it is used for" 


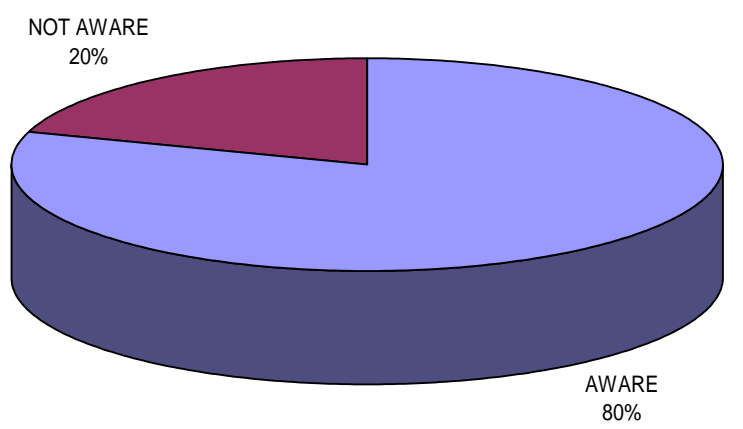

Fig. 2: The levels of awareness of ITN in Ikot Omin, Nigeria

\section{Attitude of women towards ITN}

Figure 3 illustrate that out of the 225 respondents, $208(92.4 \%)$ had a favourable attitude toward ITN while $17(7.6 \%)$ respondents had an unfavourable attitude. Those with favourable attitude felt that all pregnant mothers and children should always use ITN and agreed to advocate for its use by all pregnant women and under five children. They also indicated preference for its use compared to use of antimalarial medications for treatment. A discussant stated: When it comes to this treated nets I prefer it to continuous buying of malaria drugs" another added "prevention is better than cure" Majority of the discussants really accepted the net especially since it was given free of charge as noted by some participants "we like the net, it shows government concern for us even when I cannot use it I can't stop those that can use $i t$," another added that "it should be made available to all the inhabitants whether pregnant or not". Those with unfavourable attitude felt that environmental fumigation is much more preferable because mosquitoes bite children/adults more during the day/evenings. They noted "If the area is fumigated even once in a month by the government then we will be free day and night from mosquitoes' bite and not only in the night". Another participant added that "occasionally some of the villagers group together to fumigate their environment which renders the area free from mosquitoes for a while" Fumigation and use of insecticide spray is therefore the best remedy/strategy for preventing malaria infection from the women's perspective in this community.

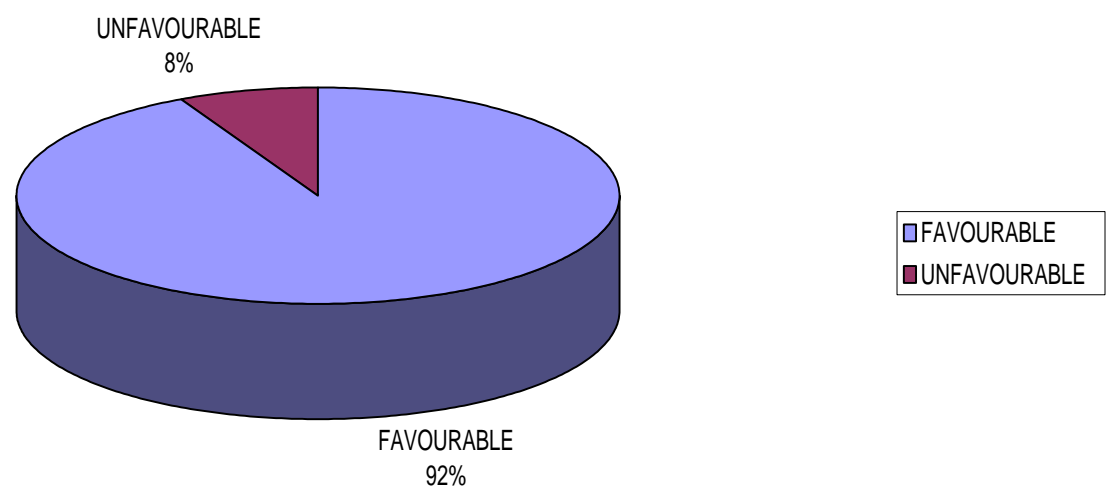

Fig. 3: Women's attitude towards ITN in Ikot Omin, Nigeria 


\section{Utilization of ITN in Ikot Omin}

One hundred and seventeen $(52.0 \%)$ out of the 225 respondents studied possess insecticide treated bed nets in their homes, while $108(48.0 \%)$ did not; out of the 117 respondents that had ITN in their homes only $53(45.3 \%)$ of the respondents slept under ITN the previous night, while $64(54.7 \%)$ of the respondents did not. A further probe on how often respondents slept under ITN showed that $28(12.4 \%)$ respondents used nets once a week, or occasionally, while 89 (39.6\%) respondents agreed that they used nets only when the weather is cold. A pregnant woman who was sweating profusely noted during the FGD "Can you expect me to sleep under that net as a nurse in this weather. It is not having the net; it is being able to sleep inside it". According to the respondents, only $9(4.0 \%)$ of respondents agreed that just one child sleep under net the previous night, while $63(28.0 \%)$ respondents said that all their children between 0-5 years sleep under nets. Generally, among the 795 children aged 0 to 5 years only $298(37.5 \%)$ children slept under the net and majority (125) were children aged 0 to 1year. A further probe as to why the children did not sleep under nets showed that, $41(18.2 \%)$ respondents said that it's so hot that their children could not sleep if the nets are used, while $9(4.0 \%)$ respondents felt that there was no need to use the ITN because, children still have malaria infection whether they slept under nets or not. One participant remarked "We have been using this net now for two months but my children are still sick as before". Though majority of the focus group discussants felt that ITN was a good governmental effort in preventing malaria, others felt that other measures such as provision of constant electricity was a better measure as it will reduce the room temperature and enhance usage of the net on hot days. A discussant observed "Madam the story would have been different with constant light supply. See even better cold water to drink we don't have" While another discussant added "tell them to do first thing, first then you ask us if we have used the net."

Similarly, over $50.0 \%$ of participants in the FGDs thought that the chemicals used to treat the nets were very harmful to adults, children and pregnant women since these chemicals could kill mosquitoes but in spite of this all participants and discussants knew that ITN was a useful preventive measure against malaria and that pregnant women and children were supposed to sleep under nets since they are the most vulnerable groups. However, the availability and use of the nets in this community was found to be very low. Over seventy five percent of the participants in the FGDs reported that very few people in the community use mosquito nets.

\section{Frequency of malaria among participants}

Among the 79 participants that were pregnant, twenty-eight $(12.4 \%)$ of the respondents reported that they have had malaria infection only once during the course of the current pregnancy, 47 (20.9\%) respondents have also had malaria infection twice or more times during the current pregnancy, while only 4 $(1.8 \%)$ have not experienced the infection during the course of the present pregnancy. It should be noted that all the respondents self-reported being on malaria prophylaxis during current pregnancy. There was a significant positive relationship between utilization of ITN and frequency of malarial attack $(r=0.725, p<0.05)$. Among the 146 mothers with children that were not pregnant, $23(10.2 \%)$ reported of malaria attack in the past one month,48 (21.3\%) within the last two months ,56 (24.9\%) within the last three months, while $19(8.4 \%)$ did not experience any malaria attack within the last three months

Among the 795 children in this study 382 $(48.1 \%)$ had malaria attack within the last one month, $256(32.2 \%)$ within the last two months, $142(17.9 \%)$ within the last three months while 15 (1.9\%) were said not to have had any malaria attack within the last three months. However, a significant positive relationship existed between sleeping under ITN and the frequency of malaria attack $(r=0.652, p<0.05)$.

\section{Factors affecting utilization of ITN}

The study revealed that the major constraint to utilization of ITN was the weather condition as 185 $(82.2 \%)$ of the respondents felt that it was really hot even without the net, talk less of sleeping under nets (Fig. 3). Epileptic electricity supply in the country is alleged by participants to have made sleeping under the net unbearable. Eighteen (8.0\%) of the respondents felt that ITN is really air tight, and discourages influx of air, but amazingly $9(4.0 \%)$ reported fear of inhaling toxic chemicals from the nets as captured in this quotation "If ants and mosquitoes could be killed within short intervals what about a human sleeping under it day in day out" Some participants 13 (5.8\%) expressed preference for other traditional methods such as environment fumigations or spraying of insecticide before bedtime. 


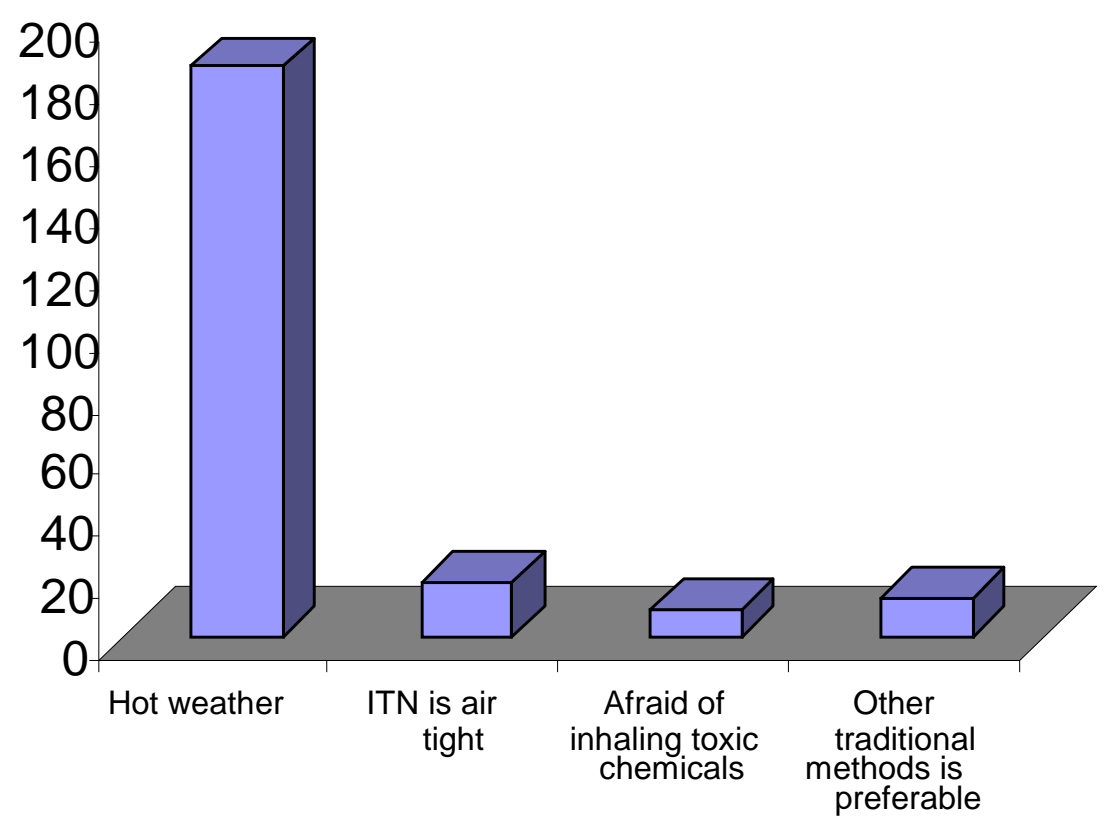

Fig. 3: Factors hindering utilization of ITN in Ikot Omin, Nigeria

\section{DISCUSSION}

Awareness of ITN among mothers was generally high although some mothers were not aware of ITN. The findings in this study is similar to Snow et al., (1999) who reported that in Uganda in which participants and key informants knew that mosquito nets were a useful preventive measure against malaria. Lack of awareness was common among those mothers who were not patronizing the community health centre. Mass media approach comprising television shows and radio jingles is used by government to disseminate current information about ITNs. This channel is dependent on electricity supply which is very irregular hence mothers miss several opportunities to listen to such messages.

Majority of the participants in all the FGDs reported that very few people in the community use mosquito nets. The costs of ITNs, followed by their nonavailability were major constraints to their use, in this community, a finding which is consistent with findings reported in previous Kenyan and Nigerian studies (Afolabi et al., 2009;Chuma et al., 2010). Utilization of ITN was really poor when compared with findings from other African countries; as only few respondents who had nets really slept under nets the previous night. Majority complained about hot and harsh weather condition; coupled with poor electricity supply in the area. This report is however contrary to the report in Mestizo communities in Peru where some net users liked the fact that the ITN kept them cool at night, but many more complained that they felt too cold sleeping under it (Harvey et al., 2008). It is thus pertinent to note the weather condition in the aforementioned communities is the opposite of what obtains in Nigeria where the temperature ranges from 22 to 33 degree centigrade, with a relative humidity ranging between 80 to $88 \%$. Thus, in the cold highlands of Nigeria for example Jos and Mambila plateau the situation in Mestizo community may be found but not in the SouthSouth zone where Calabar is located.

With regards to respondents' attitude, the respondents had a favourable attitude toward the use of ITN. This may be connected to the fact that most of the community members are familiar with the use of bed nets for the prevention of mosquito bites and so could easily advocate for the use of ITN. The findings in the present study however agree with reports from Kenya by Alaii et al. (2003) where ITN use was generally accepted among the respondents. A Ugandan study by Mbonye et al. (2006) also reported that pregnant adolescents had a favourable attitude and realize the importance of seeking preventive care for malaria through the use of ITN. The challenge among the women had had to do with the lack of support from the men who prefer buying alcoholic drinks than buying mosquito nets.

The significant positive relationship which existed between frequency of malarial attack and use of ITN suggests that if there was an effective ITN nets use by the respondents, the incidence of malaria among pregnant women and children 0-5years of age would have been greatly reduced. These findings agree with other reports which asserts for children less than five years of age, that the correct use of ITN can save about six lives for every 1,000 in sub-Saharan Africa (Lengele,2004). In the same vein, Phillips-Howard et 
al.(2003) affirmed that if infants are treated with permethrin twice a year and use bed nets, about 34.5 out of 1000 infant's lives could be save. The use of ITN has been found to be a very useful strategy for the prevention of mosquito bites and malaria attack in the tropics (Auta, 2012; Robert et al., 2003; Sachs and Malaney, 2002)

\section{CONCLUSION AND RECOMMENDATIONS}

This study has shown that awareness is high but utilization is low. A major limitation to the use of ITN among pregnant women and children 0-5 years, is a feeling of hotness during the hot weather season. A focused communication strategy to address this is highly recommended. The possibility of provision of steady light supply through the use of solar power in the homes by those who could afford it can be explored as a remedy for promoting consistent use of ITN by pregnant women and under five children in this community. Further research on the role of men is also recommended.

\section{REFERENCES}

Afolabi, B. M., Sofola, O. T., Fatunmbi, B. S., Komakech, W., Okoh, F., Oladele, Saliu O., Otsemobor, P., Oresanya, O. B., Amajoh, C. N., Fasiku, D and Jalingo, I., 2009. Household possession, use and non-use of treated or untreated mosquito nets in two ecologically diverse regions of Nigeria - Niger Delta and Sahel Savannah. Malar J.; 8(30):1475 -2875.

Alaii, J. A., Van Den Borne, H. W., Kachur, P. S., Mwenesi, H., Vulule, J. M., Hawley, W. A., Meltzer, M. I., Nalen, B. L and Phillips-Howard, P. A., 2003. Perceptions of Bed Nets and Malaria Prevention Before and After a Randomized Controlled Trial of Permethrin-Treated Bed Nets. Am. J. Trop. Med. Hyg.; 68 142-148.

Auta, A., 2012. Demographic Factors Associated with Insecticide Treated Net use Among Nigerian Women and Children. North American Journal of Medical Sciences.;4(1):40-44. doi:10.4103/1947-2714.92903.

Benjamin, G Koudou, Hala Ghattas, Clémence Essé, Christian Nsanzabana, Fabian Rohner, Jürg Utzinger, Brian E Faragher and Andres B Tschanne., 2010. The use of insecticide-treated nets for reducing malaria morbidity among children aged 6-59 months, in an area of high malaria transmission in central Côte d'lvoire.

Breman, J. G., Egan, A and Keutsch, G. T., 2001. The intolerable burden of malaria: a new look at the numbers. Am J Trop Med Hyg, 64 (Suppl 1): ivvii.

Breman, J. G., Alilio, M. S and Mills, A., 2004. Conquering the intolerable burden of malaria: what's new, what's needed: a summary. Am. J.Trop. Med. Hyg. (71):1-15.
Chuma, J., Okungu, V., Ntwiga, J., Molyneux, C., 2010. Towards achieving Abuja targets: identifying and addressing barriers to access and use of insecticides treated nets among the poorest populations in Kenya. BMC Public Health. 10 (137):1471-2458.

De Castro, M. C., Yamagata, Y., Mtasiwa, D., Tanner, M., Utzinger, J., Keiser, J and Singer, B. H., 2004. Integrated urban malaria control: a case study in Dares Salaam, Tanzania., Am. J. Trop. Med. Hyg. (71):103-117.

Desai, M., ter Kuile, F. O., Nosten, F., McGready, R., Asamoa, K., Brabin, B and Newman, R. D., 2007. Epidemiology and burden of malaria in pregnancy. Lancet Infect Dis. Feb;7(2):93-104.

Eisele, T. P., Keating, J., Littrell, M., Larsen, D and Macintyre, K., 2009. Assessment of Insecticide-Treated Bednet Use Among Children and Pregnant Women Across 15 Countries Using Standardized National Surveys. Am. J. Trop. Med. Hyg. 80(2):209- 214.

Guyatt, H. L and Snow, R. W., 2002. The cost of not treating bednets. Trends Parasitol. 18: 12-16.

Harvey, S. A., Olórtegui, M. P., Leontsini, E, Pezo, C. B., Pezantes, L. O and Winch, P. J., 2008. The Whole World Will Be Able to See Us: Determining the Characteristics of a Culturally Appropriate Bed Net Among Mestizo Communities of the Peruvian Amazon. Am. J. Trop. Med. Hyg.79(6):834-838

Killeen, G. F., Seyoum, A and Knols, B. J., 2004. Rationalizing historical successes of malaria control in Africa in terms of mosquito resource availabilty management. Am. J. Trop. Med. Hyg. 71: 87-93

Killeen, G. F., Tanner, M., Mukabana, W. R., Kalongolela, M. S., Kannady, K., Lindsay, S. W., Fillinger, U and De Castro, M. C., 2006. Habitat targeting for controlling aquatic stages of malaria vectors in Africa. Am J Trop Med Hyg. 74(4): $517-518$

Koudou, B. G., Ghattas, H., Essé, C., Nsanzabana, C., Rohner, F., Utzinger, J and Tschannen, A. B., 2010. The use of insecticide-treated nets for reducing malaria morbidity among children aged 6-59 months, in an area of high malaria transmission in central Côte d'Ivoire. Parasites \& Vectors, 3, 91. http://doi.org/10.1186/1756-3305-3-91

Lengeler, C., 2004. Insecticide-treated bednets and curtains for preventing malaria. Cochrane Database Systematic Reviews.; 2. Art. N0.: CD000363.DOI:10.1002/1465185.cd000363.pu b2.

Lengeler, C., 2002. Insecticide-treated bednets and curtains for preventing malaria (Cochrane 
Review). The Cochrane Library, Issue 2, Oxford, United Kingdom

Mbonye, A. K., Neema, S and Magnussen, P., 2006. Preventing malaria in pregnancy: a study of perceptions and policy implications in Mukono district, Uganda. Health policy and planning. 21:17-26

Mboera, L. G., Makundi, E. A., Kitua A. Y., 2007. Uncertainty in Malaria Control in Tanzania: Crossroads and Challenges for Future Interventions. Am. J. Trop. Med. Hyg. (77):112118.

Murphy, S. C and Breman, J. G., 2001. Gaps in the childhood malaria burden in Africa: cerebral malaria, neurologic sequelae, anemia, respiratory distress, hypoglycemia and complications of pregnancy. Am J Trop Med Hyg. (64): 57-67.

Phillips-Howard, P. A., Nahlen, B. L., Kolczak, M. S., ter Kuile, F. O., Alaii, J. A, Hightower, A. W., Gimnig, J., Arudo, J. A., Vulule, J., Schoute, E., Kachur, S. P., Oloo, A. J and Hawley, W. A., 2003. Efficacy of permethrintreated bed nets in the prevention of mortality in young children in an area of high perennial malaria transmission in Western Kenya. Am J Trop Med Hyg.68): 23-29
Robert, V., Macintyre, K., Keating, J., Trape, J. F., Duchemin, J. B., Warren, M and Beier, J., 2003. Malaria transmission in urban sub-Saharan Africa. Am J Trop Med Hyg. 68: 169-176.

Sachs, J and Malaney, P., 2002. The economic and social burden of malaria. Nature; 415: 680-685.

Snow, R. W., Craig, M., Deichmann, U and Marsh, K., 1999. Estimating mortality, morbidity and disability due to malaria among Africa's non-pregnant population. Bull World Health Organ. 77: 624640.

The African summit on Roll Back Malaria., 2000. Abuja, Nigeria, 25 April 2000. Geneva, World Health Organization. (document WHO/CDS/RBM/2000.17).

World Health Organization., 2002. The World Health Report 2002: Reducing risks, promoting healthy life. Geneva. World Health Organization.

WHO., 2017. Malaria: Fact sheet http://www.who.int/mediacentre/factsheets/fs094 len/ 